\title{
Exogenous spermidine alleviates oxidative damage and reduce yield loss in rice submerged at tillering stage
}

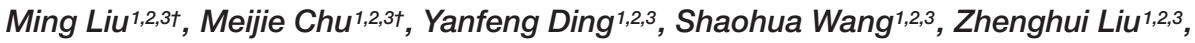 \\ She Tang ${ }^{1,2,3}$, Chengqiang Ding ${ }^{1,2,3}$ and Ganghua $\mathrm{Li}^{1,2,3 *}$ \\ ${ }^{1}$ College of Agronomy, Nanjing Agricultural University, Nanjing, China, ${ }^{2}$ Key Laboratory of Crop Physiology and Ecology in \\ Southern China, Ministry of Agriculture, Nanjing, China, ${ }^{3}$ Jiangsu Collaborative Innovation Center for Modern Crop \\ Production, Nanjing, China
}

\section{OPEN ACCESS}

Edited by:

Chun-Peng Song,

Henan University, China

Reviewed by:

Christoph Martin Geilfus,

Christian-Albrechts-Universität zu Kiel,

Germany

Haitao Shi,

Hainan University, China

*Correspondence:

Ganghua L

Igh@njau.edu.cn

${ }^{\dagger}$ These authors have contributed equally to this work.

Specialty section: This article was submitted to Plant Physiology, a section of the journal Frontiers in Plant Science

Received: 11 June 2015 Accepted: 12 October 2015 Published: 31 October 2015

Citation:

Liu M, Chu M, Ding Y, Wang S, Liu Z, Tang S, Ding C and Li G (2015) Exogenous spermidine alleviates oxidative damage and reduce yield

loss in rice submerged at tillering stage. Front. Plant Sci. 6:919. doi: 10.3389/fpls.2015.00919
To figure out whether spermidine (Spd) can alleviate oxidative damage on rice (Oryza sativa L.) caused by submergence stress, Ningjing 3 was used in this study. The results showed that, spraying Spd on rice leaves at a concentration of $0.5 \mathrm{mM}$ promoted the growth recovery of rice after drainage, such as green leaves, tillers, and aboveground dry mass. According to physiological analysis, Spd accelerate restored chlorophylls damage by submergence, and decreased the rate of $\mathrm{O}_{2}^{--}$generation and $\mathrm{H}_{2} \mathrm{O}_{2}$ content, inhibited submergence-induced lipid peroxidation. Spd also helped to maintain antioxidant enzyme activities after drainage, such as superoxide dismutase, peroxidase, and GR, which ultimately improved the recovery ability of submerged rice. With the effect of Spd, the rice yields increased by 12.1, 17.9, 13.5, and 18.0\%, of which submerged for 1, 3, 5, 7 days, respectively. It is supposed that exogenous Spd really has an alleviate effect on submergence damage and reduce yield loss of rice.

Keywords: rice, submergence stress, exogenous spermidine, tillering stage, physiological characteristics

\section{INTRODUCTION}

Paddy flood disaster is one of China's major agricultural disasters. The monsoon climate has a strong impact on the Yangtze River Basin and causes frequent flood disasters, which has brought serious threats to rice production safety. Therefore, the flood disaster has become one of the main obstacle factors limiting rice production in this area (Qin and Jiang, 2005; Huang and Qian, 2007). In the midstream and downstream of Yangtze River, panicles of rice is determined at tillering stage, when paddy fields often encounter flood disasters (Tian et al., 2005). As flood brings serious harm to the growth of rice in this period, effective measures should be took to reduce disaster losses.

Application of exogenous growth regulators is one of the effective ways to improve plant resistance of waterlogging. Studies have shown that paclobutrazol (Lin et al., 2006), proline and betaine (Hoque et al., 2007), brassinolide (BR; Li and Luo, 1999) and other exogenous regulators can effectively reduce the plant injury and yield loss caused by waterlogging. In recent years, polyamine (PAs) has been regarded as a new class of growth substances in improving plant stress resistance ability (Walters, 2003; Yuan et al., 2008). PAs are low-molecular-weight aliphatic amines that are ubiquitous in all organisms with high biological activity coming from biological metabolism. Common natural PAs include the higher PAs, spermine (Spm) and spermidine (Spd), 

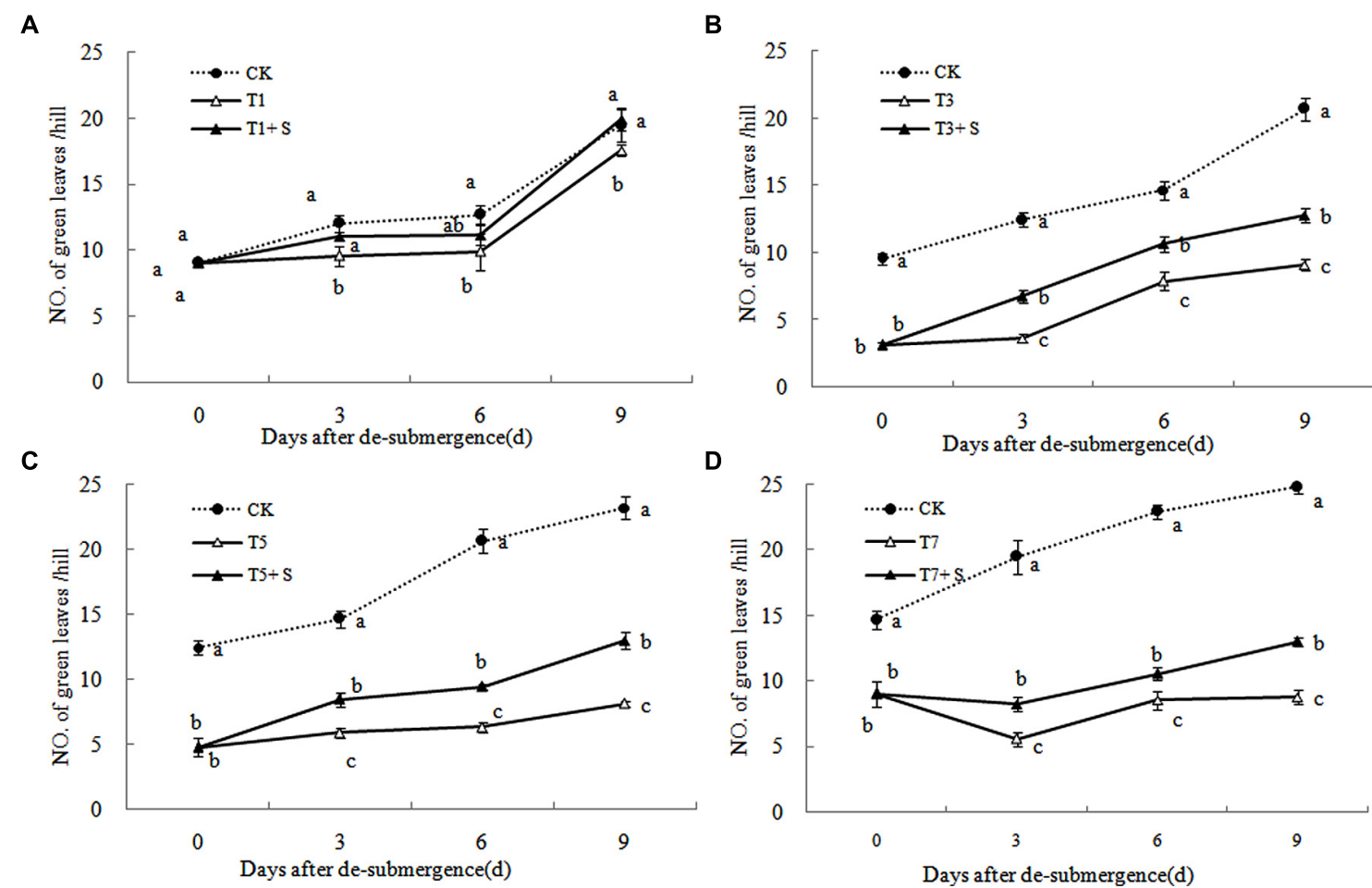

FIGURE 1 | Effects of spermidine (Spd) on green leaves number per hill of rice after submergence. CK indicate control with no submergence, T1, T3, T5, T7 indicate submerged for 1, 3, 5, 7 days, respectively. T1 + S, T3 + S, T5 + S, T7 + S indicate submerged for 1, 3, 5, 7 days and spray spermidine after drainage, respectively. The same as follow.


FIGURE 2 | Effects of Spd on tillers number per hill of rice after submergence. 
A

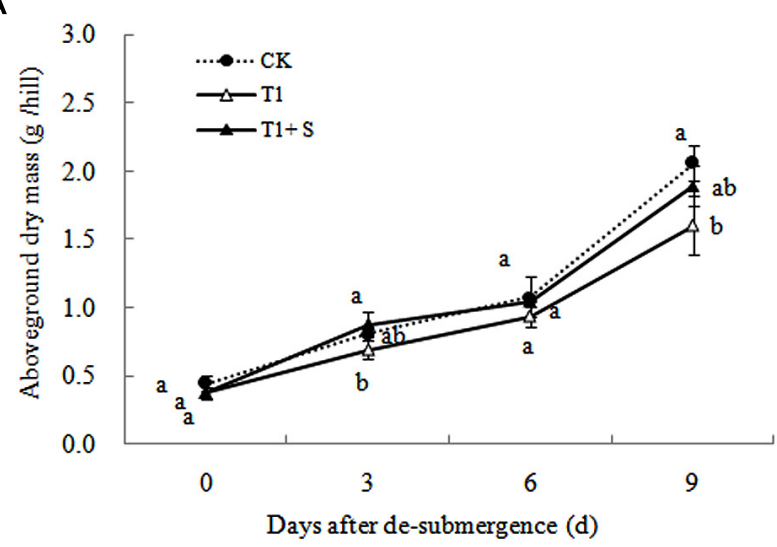

C

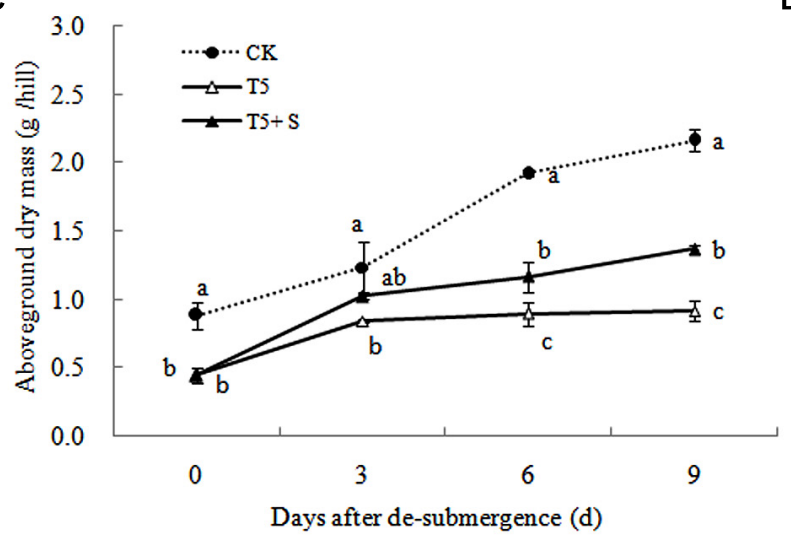

B
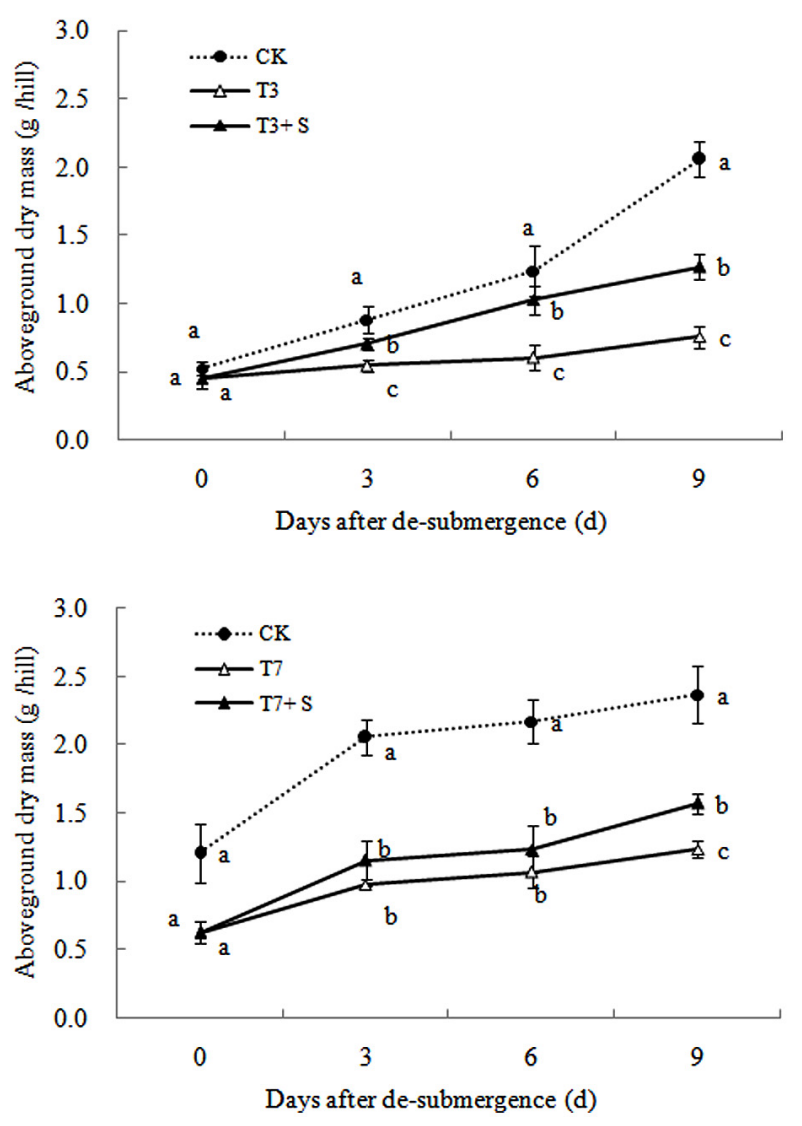

FIGURE 3 | Effects of Spd on shoot dry weight per hill of rice after submergence.

and their diamine obligate precursor putrescine (Put). Among the three major PAs, Spd is most closely associated with stress tolerance in plants (Shen et al., 2000). Spd cannot only be used as a stress protective substance directly, but also be used as a signal molecule in stress signal transduction, constructing a stress resistant mechanism (Kasukabe et al., 2004). Spraying different concentrations of Spd on Typha latifolia L. could effectively improve the AsA and GSH content, GR and APX activity, and also reduce the production of active oxygen and MDA level in leaves under $\mathrm{Cd}^{2+}$ stress (Tang et al., 2005). Spd application to salinized nutrient solution resulted in an increase in PA and proline contents and antioxidant enzyme activities in cucumber seedlings, which contributed to osmotic adjustment during salinity (Duan et al., 2008).

It has been proved that exogenous Spd can improve plant resistance to drought (Németh et al., 2002), chilling (Zheng et al., 2008), aging (Wang et al., 2000), and heat (Tian et al., 2009), but whether exogenous Spd can be used to reduce submergence damage in rice has not been shown. To answer this question, whole plant of rice were harvested from both treated and untreated plants to measure growth, yield, and antioxidant enzyme activity. The present study aims to assess the possible effect of exogenous Spd application to alleviate the damage caused by submergence stress.



FIGURE 4 | Effects of Spd on yield of rice after submergence.

\section{MATERIALS AND METHODS}

\section{Experimental Design}

The experiment was performed in 2014 growing seasons in Baolin village, Danyang County, Jiangsu province $\left(31^{\circ} 54^{\prime} \mathrm{N}\right.$, $119^{\circ} 28^{\prime} \mathrm{E}$ ). A japonica rice cultivar (Ningjing 3) popularized 



FIGURE 5 | Effects of Spd on yield traits of rice after submergence. Each data point in the spider plots represents the percentage of the mean values of the agronomic traits. The mean measurements from the CK were assigned a $100 \%$ reference value.

A



C

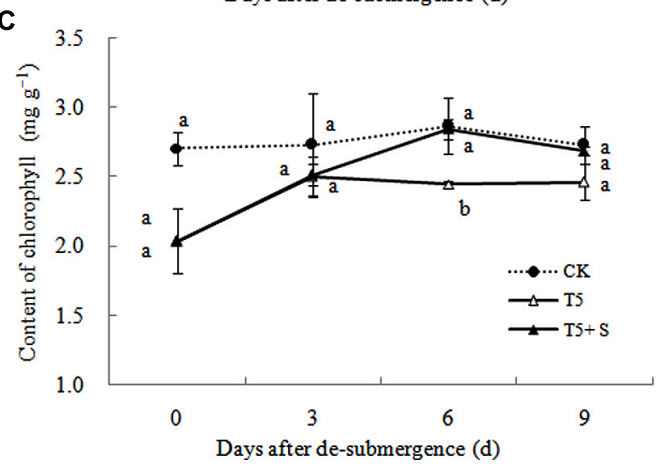

B

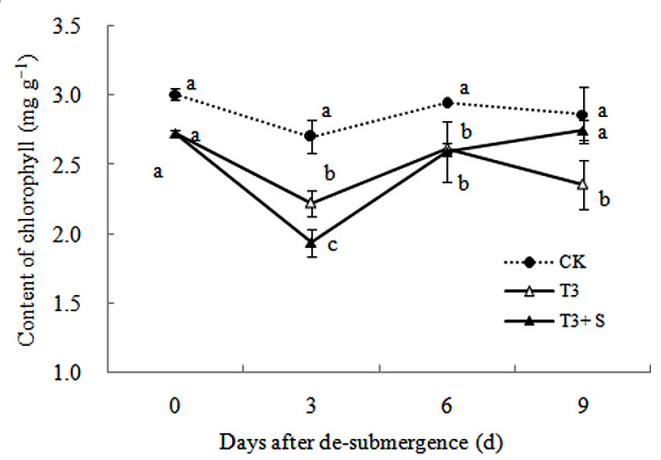

D



FIGURE 6 | Effects of Spd on chlorophyll content of rice after submergence. 
in lower reaches of the Yangtze River were grown on a farm during the rice growing seasons, which occurs from laterMay to early-November. During the last year, the species was identified as sensitive to submergence. The soil was an Orthic Acrisol, with a total nitrogen content of $1.1 \mathrm{~g} \mathrm{~kg}^{-1}$, total phosphorus content of $0.48 \mathrm{~g} \mathrm{~kg}^{-1}$, total potassium content of $1.96 \mathrm{~g} \mathrm{~kg}^{-1}$. The experiment was arranged in a completely randomized block design with three replicates. The area of a plot was $4 \mathrm{~m} \times 5 \mathrm{~m}=20 \mathrm{~m}^{2}$.

\section{Crop Management}

Seedlings 20-day-old raised in the seedling disk were transplanted in 10th June, with hill spacing of $0.3 \mathrm{~m} \times 0.13 \mathrm{~m}$ and three seedlings per hill at both sites. Nitrogen $\left(135 \mathrm{~kg} \mathrm{ha}^{-1} \mathrm{~N}\right.$ as urea), phosphorus (247 $\mathrm{kg} \mathrm{ha}^{-1} \mathrm{P}_{2} \mathrm{O}_{5}$ as single superphosphate), potassium $\left(450 \mathrm{~kg} \mathrm{ha}^{-1} \mathrm{~K}_{2} \mathrm{O}\right.$ as $\mathrm{KCl}$ ), were incorporated in plots 1 day before transplanting, additional $\mathrm{N}$ was applied 7 days after transplanting (135 kg ha-1), panicle initial (PI; $135 \mathrm{~kg} \mathrm{ha}^{-1}$ ), and the stage of the second leaf from the top extension $\left(135 \mathrm{~kg} \mathrm{ha}^{-1}\right)$.

The waterproof wall above $1 \mathrm{~m}$ was built around both sites, laying plastic film to prevent leakage. After 10 days transplanting, flooding treatment was started. The submerged water came from nearly river. Set 1, 3, 5, 7 days submergence treatments in four sites, respectively, and set a control site (CK) with no submergence. The submerged sites set a daily supplement of water to ensure complete submergence. At the end of the submergence treatments, excess water was discharged, and converted to normal field management.

Each submerged site was equally divided into two parts, separated by a ridge wrapped in plastic film. One part of each submerged site sprayed with Spd on rice leaves, which were signed as $\mathrm{T} 1+\mathrm{S}$, T3 $+\mathrm{S}$, T5 $+\mathrm{S}$, T7 $+\mathrm{S}$, and the other part sprayed with equally water, signed as T1, T3, T5, T7, respectively. We used nebulizer to sprayed $50 \mathrm{ml}$ Spd per square meter (0.5 mM, Sigma-Aldrich Chemical Co., St. Louis, MO, USA) on rice leaves at 8:00 and 18:00 in the day of drainage. Tween-20 (0.5\%, v/v; Haijiechem, Zibo, China) was used both in Spd solution $(\mathrm{T}+\mathrm{S})$ and water $(\mathrm{T})$ as a surfactant to increase adsorption, ensuring both side of the leaves were all stained with solution.

\section{Parameter Measurements}

Four plants were sampled in each sites immediately at the day flooding over (0 day), and 3, 6, 9 days after spraying Spd. The fully expanded three leaves of the two plants immediately snapfrozen in liquid nitrogen, and stored at $-40^{\circ} \mathrm{C}$ until required for analysis. The remaining two plants were oven-dried at $105^{\circ} \mathrm{C}$ for $30 \mathrm{~min}$ followed by $80^{\circ} \mathrm{C}$ for $72 \mathrm{~h}$ to constant weight. The tillers
A



C

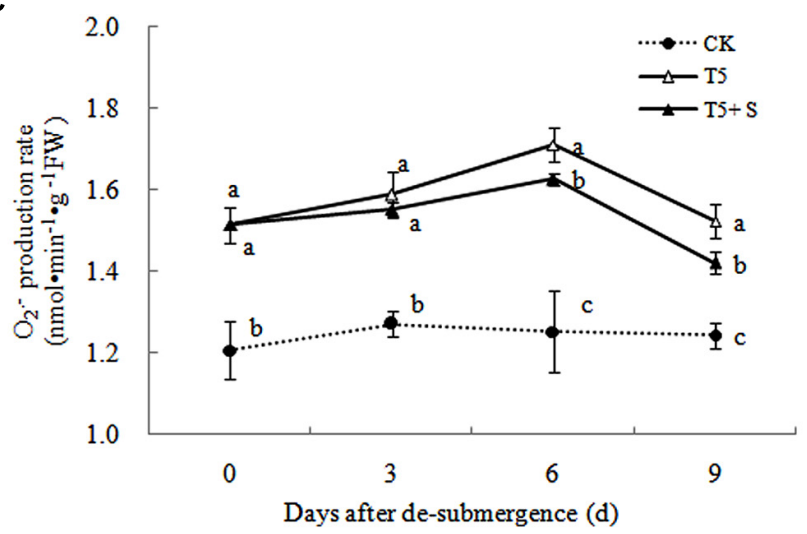

B
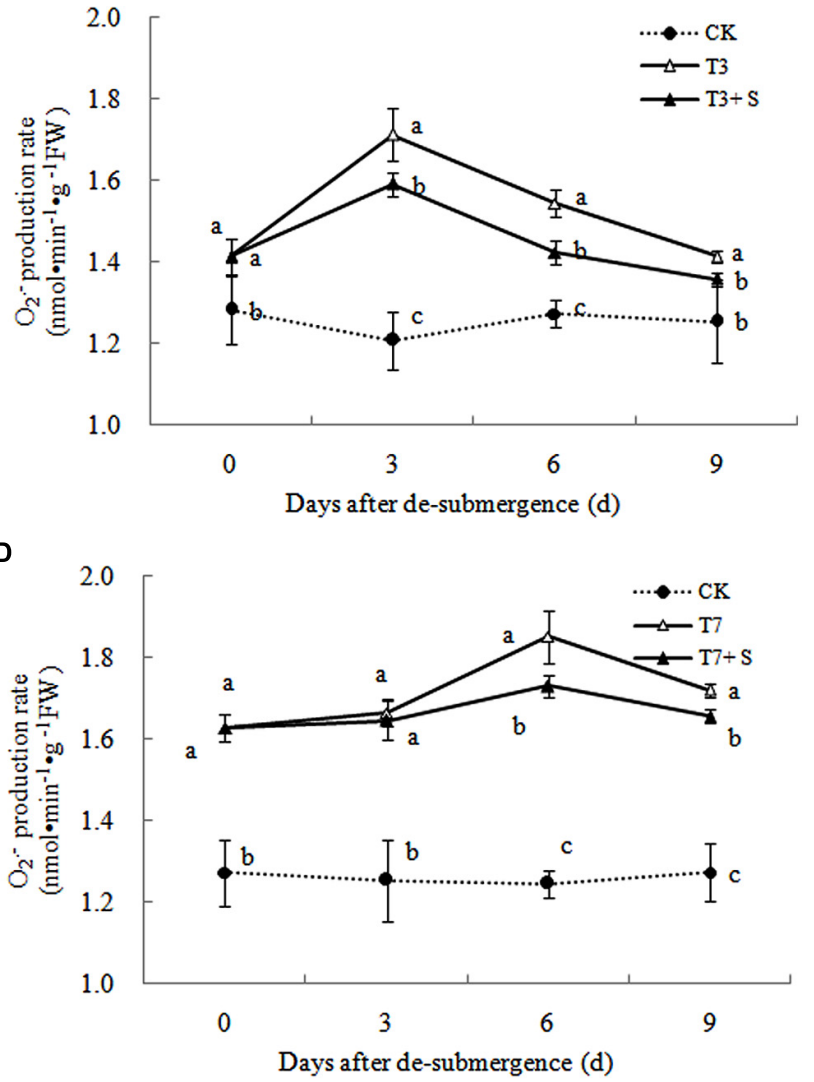

FIGURE 7 | Effects of Spd on $\mathrm{O}_{2}^{--}$production rate of rice after submergence. 

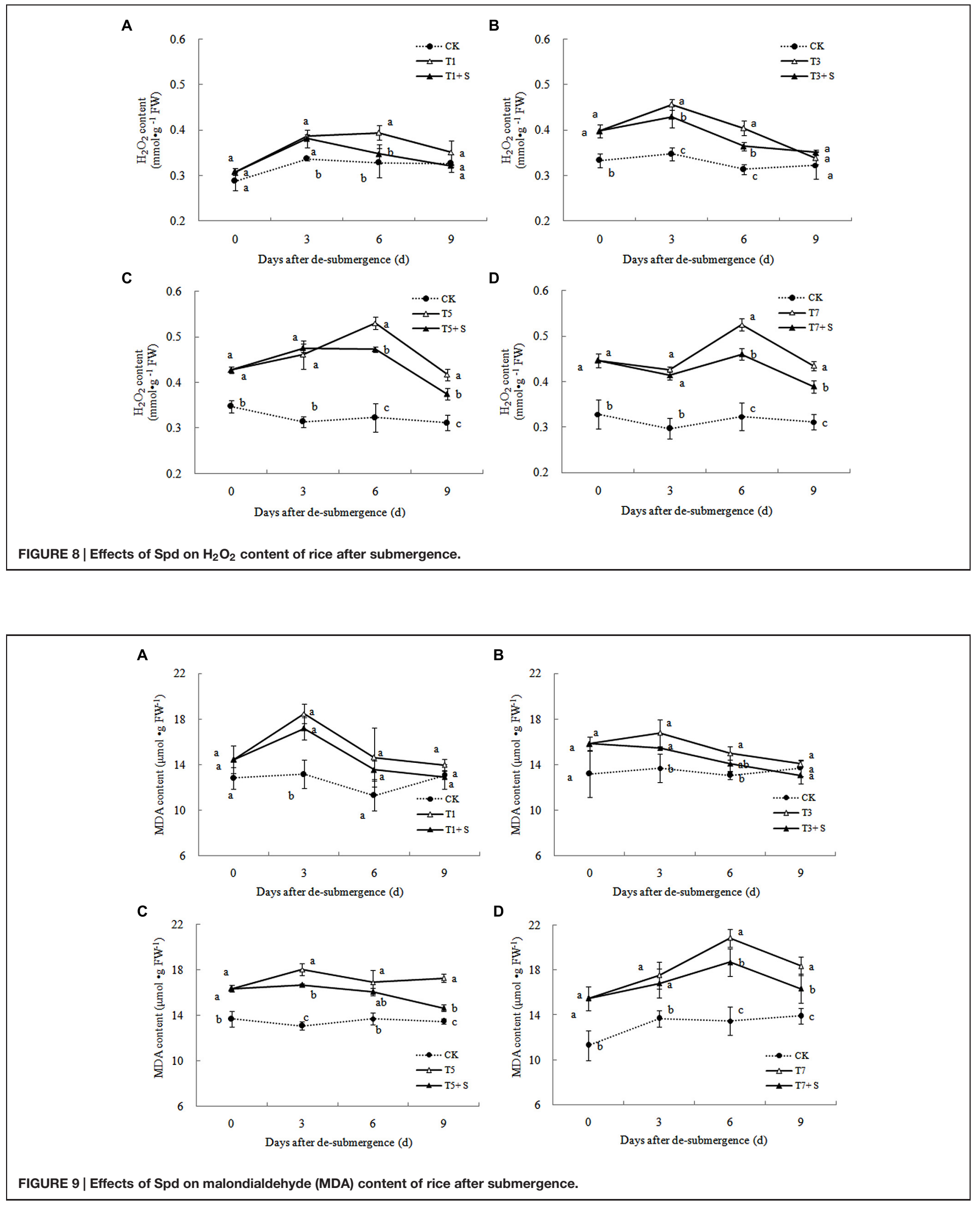
number and green leaves number per hill was counted by manual, as well as yield traits in mature stage.

Chlorophyll content was measured by the method according to a previous study $(\mathrm{Li}, 2000)$. The measurement of $\mathrm{O}_{2}^{-}$ production rate has been described previously (Wang and Luo, 1990). $\mathrm{H}_{2} \mathrm{O}_{2}$ content was measured by the kit provided by Nanjing Jiancheng Biology Company. The leave sample (0.3 g) was homogenized with a mortar and pestle in $5 \mathrm{~mL}$ icecold phosphate buffer (50 mM, pH 7.8) containing $1 \%(\mathrm{w} / \mathrm{v})$ insoluble polyvinylpolypyrrolidone (PVPP; Jiang and Zhang, 2002). The extract was centrifuged at $16,000 \times g_{\mathrm{n}}$ for $20 \mathrm{~min}$ at $4^{\circ} \mathrm{C}$. The supernatant was used to measure enzyme activity. Superoxide dismutase (SOD) activity, peroxidase (POD) activity and GR activity was measured according to the method of $\mathrm{Li}$ (2000). Malondialdehyde (MDA) content was determined by the thiobarbituric acid reaction following the method described previously (Zhao et al., 1994).

\section{Data Analysis}

All data were analyzed by SPSS (IBM SPSS statistics 20), and the results were presented as the means \pm SD. Statistically analyzed using Duncan's multiple range test at a level of significance of 0.05 . Figures were manufactured by Microsoft Excel 2007 software.

\section{RESULTS}

\section{Effects of Exogenous Spd on Growth and Yield of Submerged Rice Growth}

Except for T1 treatment, the green leaves number (Figure 1), tillers number (Figure 2) and aboveground dry mass (Figure 3) of rice were significantly decreased after submergence stress $(P<0.05)$ compared with the control, and resumed slowly after drainage. Application of exogenous SPD significantly increased the green leaves number, tillers number, and aboveground dry mass of submerged rice, effectively alleviating the submergencemediated growth reduction.

\section{Yield}

The rice yields decreased gradually with the increase of the days under submergence stress (Figure 4), especially the yields of T5 and T7 significantly decreased compared with the control (CK). Exogenous Spd apparently elevated rice yields after submergence stresses.12.1 and $17.9 \%$ of yields were increased, respectively, compared with T1 and T3, and returned to the $\mathrm{CK}$ level. Exogenous Spd also increased the yields of $\mathrm{T} 5+\mathrm{S}$ and $\mathrm{T} 7+\mathrm{S}$ by 13.5 and $18.0 \%$, respectively.
A

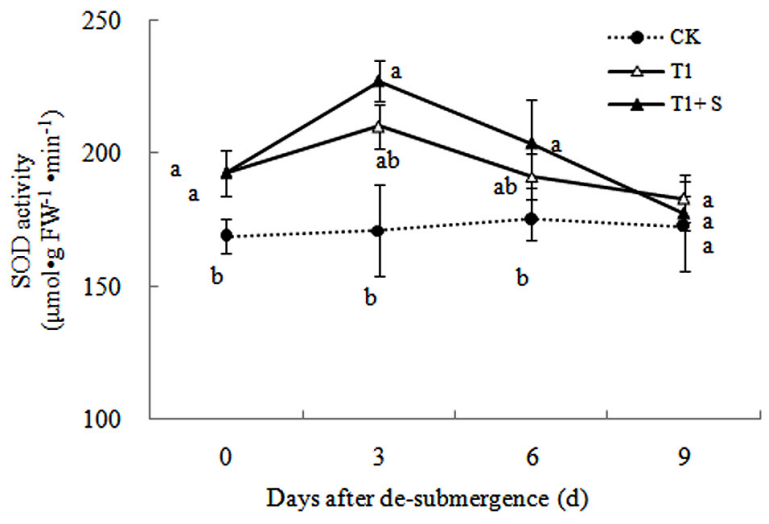

C

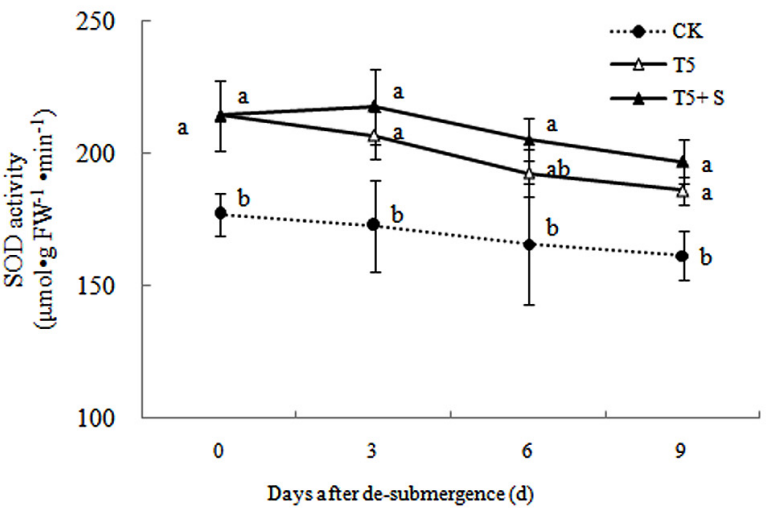

B
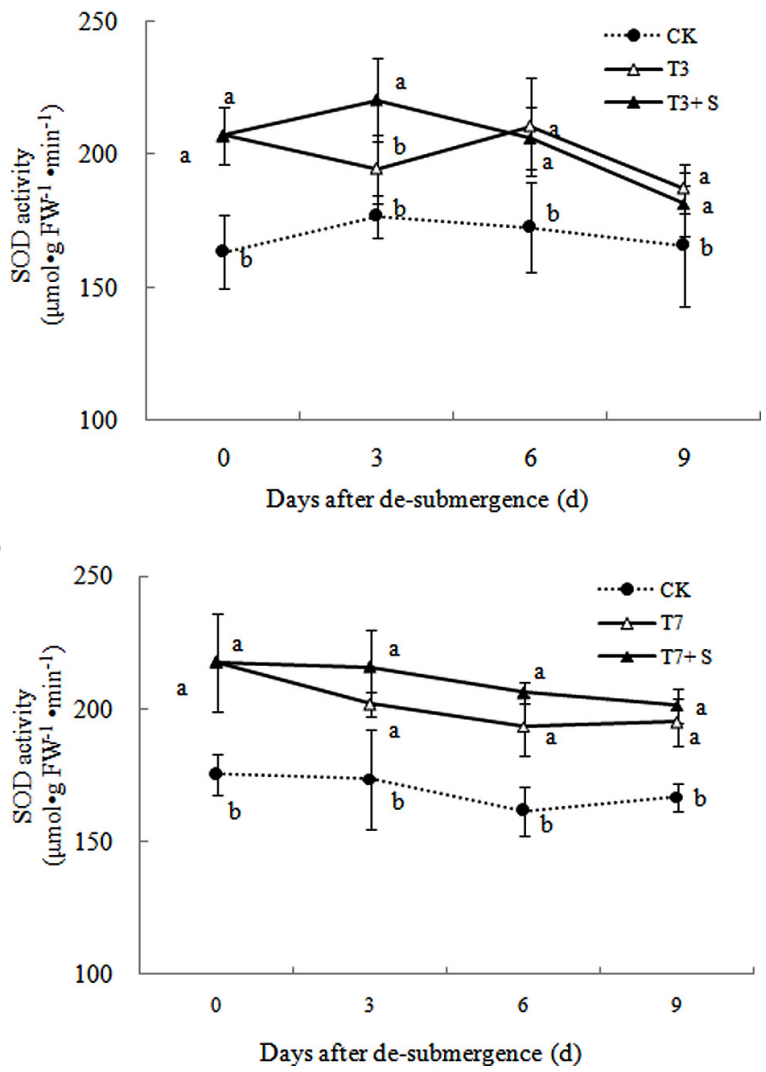

FIGURE 10 | Effects of Spd on superoxide dismutase (SOD) activity of rice after submergence. 
As for yield traits (Figure 5), panicle number and spikelet number per panicle decreased due to submergence stresses, while the seed setting rates and 1000-grain weights were less affected. Application of exogenous Spd obviously improved the panicle number and spikelet number per panicle, not the seed setting rates and 1000-grain weights.

\section{Effects of Exogenous Spd on Physiological Characteristics of Submerged Rice Chlorophyll Content}

After different days of submergence treatment, the chlorophyll content of leaves under submergence conditions was significantly lower than that of leaves under CK conditions (Figure 6). The plants applied with exogenous Spd, had an accelerate effect on the process of chlorophyll recovery, but not apparently for $\mathrm{T} 7+\mathrm{S}$.

\section{Free Radical Production and Membrane Damage}

In plants subjected to submergence stress for 3 days or longer, the $\mathrm{O}_{2}^{--}$production rate (Figure 7) and $\mathrm{H}_{2} \mathrm{O}_{2}$ content (Figure 8) significantly increased compared with CK plants. After 9 days of recovery, the $\mathrm{O}_{2}^{--}$production rate and $\mathrm{H}_{2} \mathrm{O}_{2}$ content of $\mathrm{T} 1$ and $\mathrm{T} 3$ reduced to the $\mathrm{CK}$ level, exogenous Spd accelerated this process.
This phenomenon could also found in $\mathrm{T} 5+\mathrm{S}$ and $\mathrm{T} 7+\mathrm{S}$, the $\mathrm{O}_{2}^{-}$ production rate were 6.7 and $3.8 \%$ lower than $\mathrm{T} 5$ and $\mathrm{T} 7$ at ninth day after drainage, and $\mathrm{H}_{2} \mathrm{O}_{2}$ content was 10.2 and $10.4 \%$ lower, respectively. Lipid peroxidation of membranes can be estimated from the MDA content. In submerged plants, MDA levels were significantly higher than those in the CK plants (Figure 9) at third day after drainage. The MDA contents, respectively, decreased by $7.5,7.1,15.2$, and $11.0 \%$ than water sprayed plants $(\mathrm{T})$, after 9 days of Spd treatments.

\section{Antioxidant Enzyme Activity}

Superoxide dismutase, POD, and GR were the enzymes selected to evaluate the oxidative damage caused by flooding on the antioxidant defense system. SOD activity was significantly enhanced after submergence stresses (Figure 10), and similar phenomenon were observed in POD (Figure 11) and GR (Figure 12). Whereas the activities of these enzymes turned to decline rapidly after drainage. We observed that exogenous Spd further increased the activity of SOD, 8.16, 13.31, 5.29, and $6.98 \%$ higher than T1, T3, T5 and T7 in third day after spraying, respectively. Similarly, POD and GR activities were also apparently elevated compared with the plants sprayed with water. In addition, exogenous Spd slowed down the decline of the activities of antioxidant enzymes which maintain high levels consistently.
A

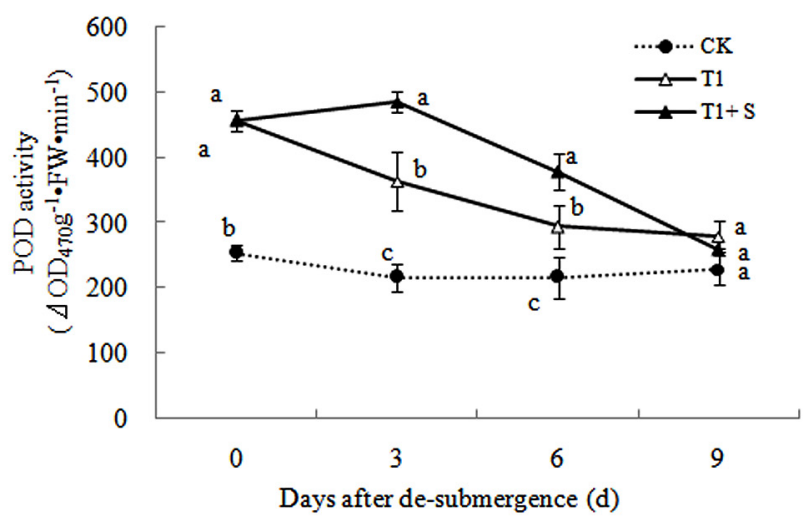

C

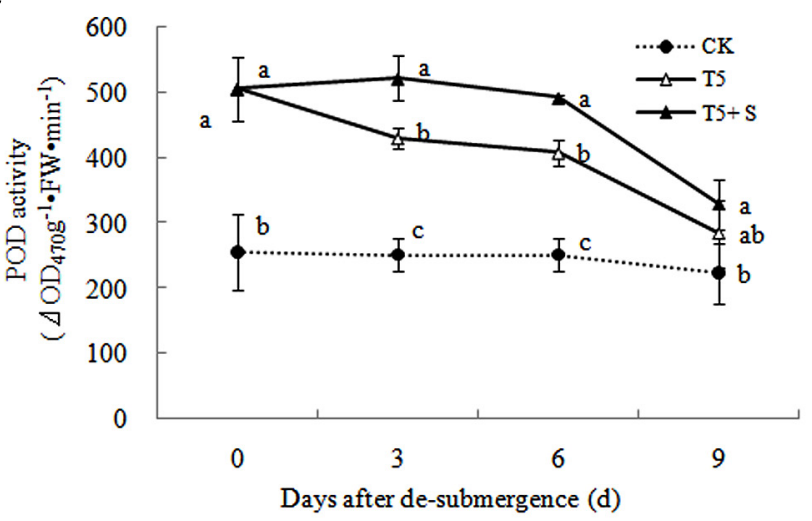

B


FIGURE 11 | Effects of Spd on peroxidase (POD) activity of rice after submergence. 


\section{DISCUSSION}

Under natural conditions, plants maintain a balance between producing and scavenging ROS through a well-coordinated and rapidly responsive antioxidant system (Bowler et al., 1992). However, diverse environmental stresses differentially affect cellular homeostasis and induce the formation of ROS, such as submergence, which causes oxidative damage to membrane and lipids (Srivalli et al., 2003). MDA content can reflect the damage degree of plants, because lipid peroxidation of membranes can be estimated from the MDA content (Liao et al., 2005). In this study, submergence stress significantly increased the levels of $\mathrm{O}_{2}^{--}$(Figure 7) and $\mathrm{H}_{2} \mathrm{O}_{2}$ (Figure 8), as well as the MDA contents (Figure 9). These indicators increased at first and then decreased after drainage, showing that submergence stress caused a delayed stress on rice, which is similar to the research on the rapeseed (Tao, 2013). Rely on the recovery abilities themselves, the MDA content, $\mathrm{O}_{2}^{-}$production rate and $\mathrm{H}_{2} \mathrm{O}_{2}$ content in the plants of $\mathrm{T} 1$ and $\mathrm{T} 3$ can return back to the normal levels after drainage. However, it was not showed in T5 and T7, probably the activities of antioxidant enzymes was stronger affected (Han et al., 2011). It is well documented that PAs can counteract oxidative damage in plants by acting as direct free radical scavengers (Drolet et al., 1986). On the other hand, Spd may act as a protectant for the plasma membrane against stress damage by maintaining membrane integrity (Tadolini et al., 1984; Tadolini, 1988). Our results showed that exogenous Spd promoted the reduction of the severe lipid peroxidation under submergence stress (Figures 7-9), which is in agreement with the previous report (Yiu et al., 2009).

It has been reported that a major role of oxygen radicals in chlorophyll destruction by waterlogging in mung bean leaves is indicated (Ahmed et al., 2002). It was also found in this study that chlorophyll significantly decreased in rice leaves under submergence stress (Figure 6). Lower chlorophyll would turn the leaves yellow, resulting in a decline in photosynthesis and photosynthetic products, thus affects plant physiological metabolism (Zahed et al., 2009). Our results showed that chlorophyll losses were effectively reversed by the exogenous Spd (Figure 6), which was consistent with other study (Wang et al., 2000). The increased chlorophyll content in leaves perhaps has an important role to promote the growth of tillers and leaves and increase dry matter of rice (Figures 1-3).

The major ROS-scavenging enzymes of plants include SOD, POD, CAT, APX, and GR. SOD converts $\mathrm{O}_{2}^{--}$to $\mathrm{H}_{2} \mathrm{O}_{2}$ (Alscher et al., 2002), whereas POD, CAT, and GR help to minimize the damaging effects of $\mathrm{H}_{2} \mathrm{O}_{2}$ by converting it into oxygen and water (Peters et al., 1989; Liu et al., 2009). With the action of the enzymes, the MDA content, $\mathrm{O}_{2}^{--}$production rate
A

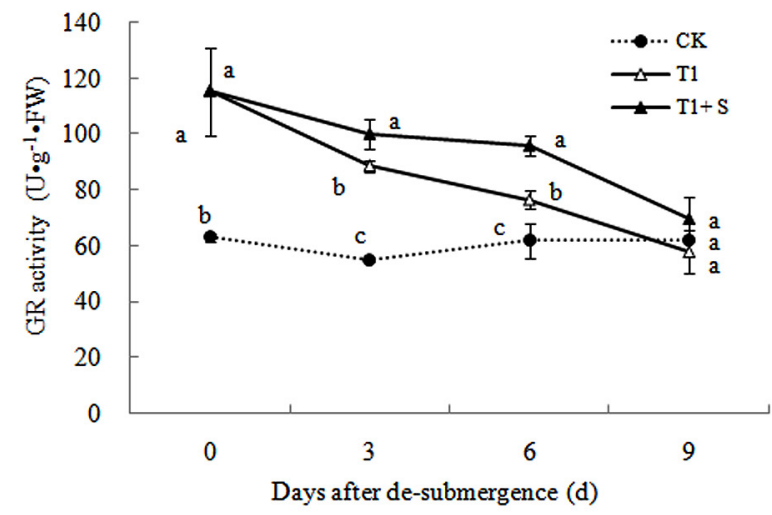

C

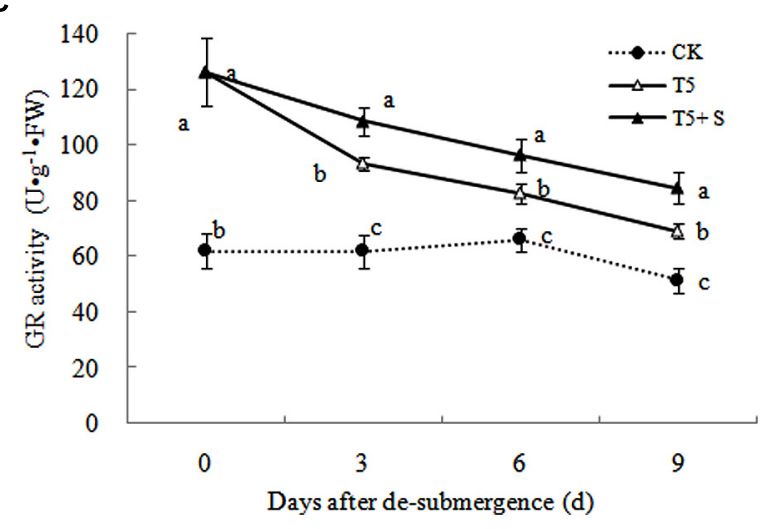

B

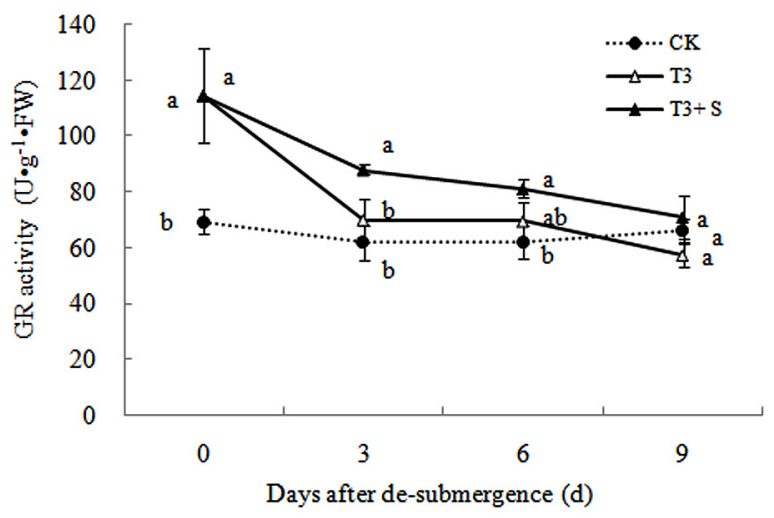

D

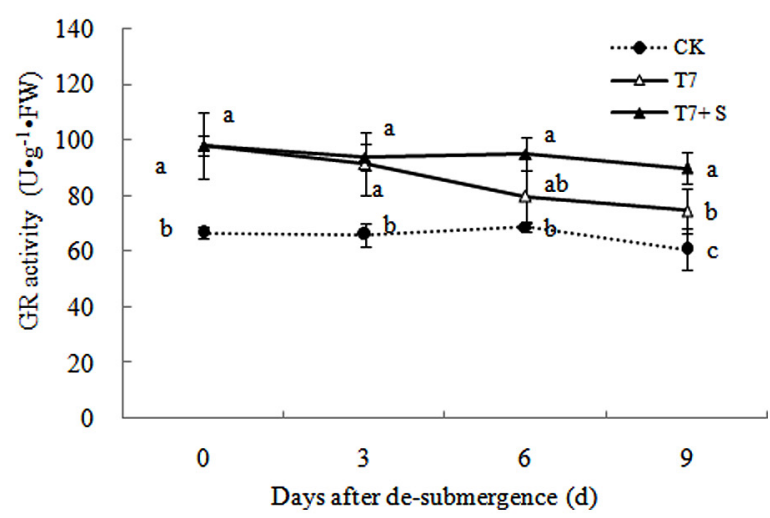

FIGURE 12 | Effects of Spd on GR activity of rice after submergence. 
and $\mathrm{H}_{2} \mathrm{O}_{2}$ content showed a trend of decline (Figures 7-9). Previous research indicated that exogenous Spd could increase antioxidant enzymes activities in plant under stress ( $\mathrm{Xu}$ et al., 2001; Kasukabe et al., 2004; Tang and Newton, 2005). Our study found that exogenous Spd not only promoted the activities of SOD, POD, and GR, but also delayed the rate of decline in these enzymes activities (Figures 10-12). Maintaining a high level of activities can ensure the efficient removal of ROS (Huang et al., 1990; Jiang et al., 1992; Xie et al., 1998). The probably reason for Spd acting as an inhibitor of ROS production is that Spd can scavenge ROS directly (Drolet et al., 1986) or indirectly by improving antioxidant enzyme activities, through combining with antioxidant enzymes molecule (Slocum et al., 1984; Mehta et al., 1991). In this study, how Spd scavenge ROS is unclear, which may need further research to verify it.

Submergence stress causes adverse effects on plant growth and productivity (Boru et al., 2001; Wang et al., 2007). Growth analysis is widely used as a tool to characterize plant growth. Our results showed that exogenous Spd sprayed on rice leaves significantly alleviated the growth inhibition by submergence stress, increasing green leaves (Figure 1), tillers (Figure 2), and biomass accumulation (Figure 3 ).

Damage of submergence stress on rice was ultimately reflected on yield. Our results showed that the panicle number and the spikelet number per panicle of rice significantly decreased under submergence stress (Figure 5), leading to a decline of yield (Figure 4). The longer under submergence, the more yield decreased (Lin et al., 1997). Submergence stress seriously affected

\section{REFERENCES}

Ahmed, S., Nawata, E., Hosokawa, M., Domae, Y., and Sakuratani, T. (2002). Alterations in photosynthesis and some antioxidant enzymatic activities of mungbean subjected to waterlogging. Plant Sci. 163, 117-123. doi: 10.1016/S0168-9452(02)00080-8

Alscher, R. G., Erturk, N., and Heath, L. S. (2002). Role of superoxide dismutases (SODs) in controlling oxidative stress in plants. Exp. Bot. 53, 1331-1341. doi: 10.1093/jexbot/53.372.1331

Boru, G., Van Ginkel, M., Kronstad, W. E., and Boersma, L. (2001). Expression and inheritance of tolerance to waterlogging stress in wheat. Euphytica 117, 91-98. doi: 10.1023/A:1003929803920

Bowler, C., Montagu, M., and Inze, D. (1992). Superoxide dismutase and stress tolerance. Annu. Rev. Plant Biol. 43, 83-116. doi: 10.1146/annurev. pp.43.060192.000503

Drolet, G., Dumbroff, E. B., Legge, R. L., and Thompson, J. E. (1986). Radical scavenging properties of polyamines. Phytochemistry 25, 367-371. doi: 10.1016/S0031-9422(00)85482-5

Duan, J., Li, J., Guo, S., and Kang, Y. (2008). Exogenous spermidine affects polyamine metabolism in salinity-stressed Cucumis sativus roots and enhances short-term salinity tolerance. J. Plant Physiol. 165, 1620-1635. doi: 10.1016/j.jplph.2007.11.006

Han, L. L., Zhou, Q., Chen, W. P., Tian, Y. D., Xing, X. H., Xing, H., et al. (2011). Effects of flooding on growth and yield of soybean. Soyb. Sci. 30, 589-595.

Hoque, A., Okuma, E., Banu, N. A., Nakamura, Y., Shimoishi, Y., and Murata, Y. (2007). Exogenous proline mitigates the detrimental effects of salt stress more than exogenous betaine by increasing antioxidant enzyme activities. J. Plant Physiol. 164, 553-561. doi: 10.1016/j.jplph.2006.03.010

Huang, D. Q., and Qian, Y. F. (2007). The elementary analysis of summer extreme precipitation events simulated by community climate model 3. J. Nanjing Univ. Nat. Sci. 43, 238-248.

Huang, W. Y., Wang, Y. L., and Yuan, L. J. (1990). The relationship between polyamines and senescence of detached wheat leaves. Acta Bot. Sin. 32, 125-132. the growth of tillers (Figure 2), thus led to the significant decrease of the panicle number. The spikelet number per panicle are closely associated with nutrient levels at tillering stage (Mae, 1997), which is the reason why the spikelet number per panicle declined resulted from the decrease of biomass accumulation. The exogenous Spd significantly improved the panicle number, the spikelet number per panicle and grain yields of rice (Figures 4 and 5), probably resulting from the raising of the green leaves, tillers, and biomass accumulation (Figures 1-3). We found that spraying Spd increased rice yields by more than 10\%, indicating that the exogenous Spd plays an important role in reducing the yield loss.

\section{AUTHOR CONTRIBUTIONS}

GL conceived and designed the experiments. YD and SW performed the experiments. ML analyzed the data. ML and MC wrote the paper.

\section{FUNDING}

This work was supported by the Key Technologies R\&D Program of China during the 12th Five-Year Plan period (2012BAD20B05, 2013BAD20B05, 2013BAD07B09, 2012BAD04B08), the Fundamental Research Funds for the Central Universities (KYTZ201402).

Jiang, L., Shen, Z., Zhang, Z., and Yan, J. (1992). The effects of polyamines on metablism of active oxygen in datached leaves of Hordeum vulgare var. nudum hook. f. Molecularplant 19, 367-371.

Jiang, M., and Zhang, J. (2002). Water stress-induced abscisic acid accumulation triggers the increased generation of reactive oxygen species and up-regulates the activities of antioxidant enzymes in maize leaves. J. Exp. Bot. 53, 2401-2410. doi: 10.1093/jxb/erf090

Kasukabe, Y., He, L. X., and Nada, K. (2004). Overexpression of spermidine synthase enhances tolerance to multiple environmental stresses and upregulates the expression of various stress-regulated genes transgenic Arabidopsis thaliana. Plant Cell Physiol. 45, 712-722. doi: 10.1093/pcp/ pch083

Li, H. S. (ed.). (2000). Principles and Techniques of Plant Physiology and Biochemistry Experiments. Beijing: Higher Education Press.

Li, X., and Luo, B. (1999). Effect of brassinosteroids on the waterlogging resistance of wheat at booting stage. J Triticeae Crops 20, 63-66.

Liao, B. H., Liu, H. Y., Zeng, Q. R., Yu, P. Z., Probst, A., and Probst, J. L. (2005). Complex toxic effects of and acid rain on growth of kidney bean (Phaseolus vulgaris L.). Environ. Int. 31, 891-895. doi: 10.1016/j.envint.2005. 05.029

Lin, K. H. R., Tsou, C. C., Hwang, S. Y., Chen, L. F. O., and Lo, H. F. (2006). Paclobutrazol pre-treatment enhanced flooding tolerance of sweet potato. J. Plant Physiol. 163, 750-760. doi: 10.1016/j.jplph.2005.07.008

Lin, W. H., Sun, F. Z., Peng, K. Q., Li, L. N., Wang, H. Q., and Xia, W. (1997). Effect of rice yield and yield components under submergence stress. J. Hunan Agric. Univ. 23, 50-54.

Liu, Z., Zhang, X., Bad, J., Suo, B. X., Xu, P. L., and Wang, L. (2009). Exogenous paraquat changes antioxidant enzyme activities and lipid peroxidation in drought-stressed cucumber leaves. Sci. Hortic. 121, 138-143. doi: 10.1016/j.scienta.2009.01.032

Mae, T. (1997). "Physiological nitrogen efficiency in rice: nitrogen utilization, photosynthesis, and yield potential," in Plant Nutrition for Sustainable Food Production and Environment, ed. T. Mae (Amsterdam: Springer), 51-60. 
Mehta, A. M., Saftner, R. A., Schaeffer, G. W., and Mattoo, A. K. (1991). Translational modification of an 18 kilodalton polypeptide by spermidine in rice cell suspension cultures. Plant Physiol. 95, 1294-1297. doi: 10.1104/pp.95.4.1294

Németh, M., Janda, T., and Horvath, E. (2002). Exogenous salicylicacid increases polyamine content but may decrease drought tolerance in maize. Plant Sci. 162, 569-574. doi: 10.1016/S0168-9452(01)00593-3

Peters, J. L., Castillo, F. J., and Heath, R. H. (1989). Alteration of extracellular enzymes in pinto bean leaves upon exposure to air pollution, ozone and sulfur dioxide. Plant Physiol. 89, 159-164. doi: 10.1104/pp.89.1.159

Qin, N.-X., and Jiang, T. (2005). GIS based risk zoning and assessment of flood disaster in them idle and lower reaches of the Yangtze River Basin. J. Nat. Dis. $14,5-11$.

Shen, W., Nada, K., and Tachibana, S. (2000). Involvement of polyamines in the chilling tolerance of cucumber cultivars. Plant Physiol. 124, 431-440. doi: $10.1104 /$ pp.124.1.431

Slocum, R., Kaur-Sawhney, R., and Galston, A. W. (1984). The physiology and biochemistry of polyamines in higher plants. Arch. Biochem. Biophys. 235, 283-303. doi: 10.1016/0003-9861(84)90201-7

Srivalli, B., Chinnusamy, V., and Khanna-Chopra, R. (2003). Antioxidant defense in response to abiotic stresses in plants. J. Plant Biol. New Delhi 30, 121-140.

Tadolini, B. (1988). Polyamine polyamine inhibition of lipoperoxidation. The influence of polyamines on iron oxidation in the presence of compounds mimicking phospholipid polar heads. Biochem. J. 249, 33-36. doi: 10.1042/bj2490033

Tadolini, B., Cabrini, L., Landi, L., Varani, E., and Pasquali, P. (1984). Polyamine binding to phospholipid vesicles and inhibition of lipid peroxidation. Biochem. Biophys. Res. Commun. 122, 550-555. doi: 10.1016/S0006-291X(84)80068-6

Tang, C. F., Liu, Y. G., Zeng, G. M., Li, X., Xu, W. H., Li, C. F., et al. (2005). Effects of exogenous spermidine on antioxidant system responses of Typha latifolia L. under Cd2 + stress. J. Integr. Plant Biol. 47, 428-434. doi: 10.1111/j.17447909.2005.00074.x

Tang, W., and Newton, R. J. (2005). Polyamines reduce salt-induced oxidative damage by increasing the activities of antioxidant enzymes and decreasing lipid peroxidation in Virginiapine. Plant Growth Regul. 46, 31-43. doi: 10.1007/s10725-005-6395-0

Tao X. (2013). The Research on Mechanisms of Waterlogging Stress of Rapeseed and Mitigative Effects of Exogenous Iaa on Waterlogging Damage. M.S. thesis. Nanjing Agricultural University, Nanjing.

Tian, J., Guo, S. R., Liu, X. E., RunHua, Z., and YuJing, C. (2009). Effects of exogenous spermidine pretreatment on antioxidant system in cucumber seedling leaves under high temperature stress. Acta Bot. Bor-Occid Sin. 29, 2261-2267.

Tian, X. R., Jiang, A. J., Gao, P., and Zhang, Z. (2005). Contrastive analysis of plum rains floods in typical years in Jiangsu Province. J. Nat. Dis. 14, 12-17.
Walters, D. R. (2003). Polyamines and plant disease. Phytochemistry 64, 97-107. doi: 10.1016/S0031-9422(03)00329-7

Wang, A. G., and Luo, G. H. (1990). Quantitative relation between the reaction of hydroxylamine and superoxide anion radicals in plants. Plant Physiol. Commun. 6, 55-57.

Wang, F., Zhao, T., and Gai, J. (2007). Evaluation, eco-region characterization and elite germpalsm identification of submergence tolerance at seeding stage in wild and cultivated soybeans. Soyb. Sci. 26, 525-534.

Wang, X. Y., Li, X. D., and Zou, Q. (2000). Effect of polyamines on senescence of attached peanut leaves. Sci. Agric. Sin. 33, 30-35.

Xie, Y. F., Shen, H. J., and Li, M. Z. (1998). Effects of acid stress on endogenous polyamine and active oxygen metabolism of woody plants. Sci. Silve Sin. 35, $117-121$.

Xu, Y. C., Wang, J., Liu, H., and Wang, G. (2001). Promoting effect of exogenous spermine on antioxidative enzyme activity in wheat seedlings. Acta Phytophysiol. Sin. 27, 349-352.

Yiu, J. C., Liu, C. W., Fang, D. Y. T., and Lai, Y. S. (2009). Waterlogging tolerance of Welsh onion (Allium fistulosum L.) enhanced by exogenous spermidine and spermine. Plant Physiol. Biochem. 47, 710-716. doi: 10.1016/j.plaphy.2009.03.007

Yuan, Z. L., Liu, X. M., and Li, H. X. (2008). Review on the relationship between polyamines and environmental stress. Acta Bot. Bor-Occid Sin. 28, 1912-1919.

Zahed, H., Maria, F. L. C., Vicent, A., Pérez-Clemente, R. M., and GómezCadenas, A. (2009). Modulation of the antioxidant system in citrus under waterlogging and subsequent drainage. J. Plant Physiol. 166, 1391-1404. doi: 10.1016/j.jplph.2009.02.012

Zhao, S. J., Xu, C. C., Zou, Q., and Meng, Q. W. (1994). Improvements of method for measurement of malondialdehyde in plant tissues. Plant Physiol. Commun. 30, 207-210.

Zheng, Y. Y., Cao, D. D., and Zhang, S. (2008). Effect of polyamines on chilling tolerance in seed imbibition and seed germination in maize. Acta Agron. Sin. 34, 261-267. doi: 10.3724/SP.J.1006.2008.00261

Conflict of Interest Statement: The authors declare that the research was conducted in the absence of any commercial or financial relationships that could be construed as a potential conflict of interest.

Copyright (C) 2015 Liu, Chu, Ding, Wang, Liu, Tang, Ding and Li. This is an openaccess article distributed under the terms of the Creative Commons Attribution License (CC BY). The use, distribution or reproduction in other forums is permitted, provided the original author(s) or licensor are credited and that the original publication in this journal is cited, in accordance with accepted academic practice. No use, distribution or reproduction is permitted which does not comply with these terms. 